\title{
Role of Ultrasound in the Diagnosis and Management of Gall Bladder Diseases
}

\author{
Md. Abul Hasanat ${ }^{1}$, Farida Yasmin Shelly ${ }^{2}$, Monowara Begum ${ }^{3}$, Md. Durul Huda ${ }^{4}$, Md. Masudul Hasan Khan ${ }^{5}$
}

\begin{abstract}
:
Background \& objective: The majority of published data on the sensitivity and specificity of ultrasound (US) in the diagnosis of gallbladder pathology was conducted over 30 years ago. Since then the quality and resolution of ultrasonography has improved significantly. It is, therefore, essential to asses afresh whether the progression in technology has translated into improved diagnostic accuracy. The present study was undertaken to find the usefulness of US in diagnosing gallbladder diseases with particular reference to cholecystitis and gall bladder carcinoma.

Methods: This cross-sectional observational study was conducted at the Department of Radiology and Imaging, Rajshahi Medical College, Rajshahi in collaboration with the Departments of General Surgery and Histopathology of the same Medical College between July 2016 to June 2018. A total of 128 patients were initially included on the basis of signs and symptoms of gallbladder diseases. All these patients were subjected to abdominal US to achieve a ultrasonic diagnosis of gall bladder disease followed by histopathological examination of biopsy material taken from the gall bladder or specimen of the operated gall bladder. The accuracy of ultrasound in the diagnosis of gall bladder diseases was determined by comparing the ultrasound sound diagnosis with that of histopathological diagnosis. In particular, the role of ultrasound was evaluated in the differentiation of benign gall bladder diseases from those of malignant ones.
\end{abstract}

Result: Age distribution of the patients shows that over one-third (35.9\%) was $\geq 50$ years old followed by $24.9 \%$ $40-50$ years, $21.9 \% 30-40$ years and $16.4 \% 20-30$ years old with mean age of the patients being 43.8 (range: $18-80$ ) years. Females outnumbered males by roughly $11: 9$. In terms of BMI, $6.2 \%$ were underweight, $16.4 \%$ overweight, and $4.7 \%$ obese. The predominant complaints reported by the patients were pain in the right upper abdomen $(95.3 \%)$, epigastric pain $(94.7 \%)$, abdominal discomfort $(96.9 \%)$ followed by nausea $(75 \%)$, low-grade fever $(37.5 \%)$, jaundice $(26.6 \%)$ and vomiting $(26.6 \%)$. Approximately $44 \%$ of the patients exhibited anaemia. Nearly half $(46.1 \%)$ of the patients exhibited sonographic Murphy's sign. Hyperechoic echo character was invariably obtained with $12.5 \%$ cases having hypoechoeic character as well. Over $90 \%$ of the patients had gall-stones, $62.5 \%$ cholecystitis (thickened gall-bladder wall). Ultrasound comment on the type of diseases revealed that $112(87.5 \%)$ were benign diseases and $16(12.5 \%)$ malignant cases. Approximately $55 \%$ of the gall bladder diseases diagnosed by histopathology were cholecystitis. Histopathological comment shows that about $90 \%$ of the diseases were benign and the rest $(10.2 \%)$ were malignant. The sensitivity of ultrasound in diagnosing cholecystitis was $85.9 \%$, while the specificity of the test was $60.9 \%$ with overall diagnostic accuracy of the test being $73.4 \%$. The US had a optimum sensitivity (84.6\%) and high specificity $(95.6 \%)$ in diagnosing gall-bladder carcinoma.

Conclusion: The study concluded that US could be considered as the preferred initial imaging technique for patients who are clinically suspected of having acute calculous cholecystitis. It is also a useful imaging modality for diagnosing gall-bladder malignancy. Thus, US can be dependably used in the primary evaluation of heptobilliary pathology.

Key Word: Ultrasound, Gall Bladder Diseases, Cholecystitis, Gall Bladder Malignancy etc.

\section{Authors' information:}

${ }^{1}$ Dr. Md. Abul Hasanat, Junior Consultant (Anaesthesia), OSD, DGHS, Attached Rajshahi University, Bangladesh

${ }^{2}$ Dr. Farida Yasmin Shelly, MBBS; MPH; DMU; PhD, Associate Professor, School of Science \& Technology, Bangladesh Open University, Gazipur.

${ }^{3}$ Dr. Monowara Begum, FCPS, DGO (Obstetrics \& Gynaecology), Consultant, Rajshahi Medical College Hospital, Rajshahi

${ }^{4}$ Dr. Md. Durul Huda, Assistant Professor, Institute of Health Technology, Rajshahi, Bangladesh

${ }^{5}$ Dr. Md. Masudul Hasan Khan, Professor, Department of Biochemistry and Molecular Biology, University of Rajshahi, Bangladesh

Correspondence: Dr. Md. Masudul Hasan Khan, Phone: +880 17140999666, E-mail:drmuktabio@gmail.com 


\section{INTRODUCTION:}

Hepatobiliary disease is a common problem in patients presenting to emergency departments or primary care settings. Unfortunately, clinical examinations and laboratory evaluations lack the necessary sensitivity and specificity to accurately diagnose many of these entities without further testing. ${ }^{1}$ Emergency conditions involving the gallbladder $\&$ the bile ducts are common radiological challenging problems ${ }^{2}$ although imaging provides valuable information 1) for the final diagnosis of acute cholecystitis (as up to $20 \%$ of the patients clinically classified as having acute cholecystitis have another disease that does not require surgery), 2) to prevent the patient from complications in case of delayed diagnosis and 3) to detect complications which may urge the surgical treatment. ${ }^{3}$

Ultrasound (US) is the preferred imaging examination for the diagnosis of acute cholecystitis and is the first method used when the clinical presentation is suggestive of biliary pathology because of its high sensitivity at the detection of GB stones, its real-time character, and its speed and portability. The main findings of acute calculous cholecystitis on US include in addition to the presence of stones: distension of the gallbladder lumen, gallbladder wall thickening, a positive US Murphy sign, pericholecystic fluid. ${ }^{4,5}$ Ultrasound has the best sensitivity and specificity for evaluating patients with suspected gallstones. ${ }^{6}$ As reported in the literature, ${ }^{7}$ some ultrasonographic findings are more strongly associated with acute cholecystitis than others: a positive Murphy's sign (pain is provoked by either the transducer or the sonographer's palpation under guidance, in the exact area of the gallbladder) is reported to have sensitivity as high as $88 \% .{ }^{8,9}$ Ralls et al. ${ }^{10}$ report that one of the most important advantages of ultrasound over other imaging techniques in the investigation of acute cholecystitis is the ability to assess for a sonographic Murphy sign, which is a reliable indicator of acute cholecystitis with a sensitivity of $92 \%$. An increased gallbladder wall thickness of $>3.5 \mathrm{~mm}$ has been found to be a reliable and independent predictor of acute cholecystitis. ${ }^{11}$ Visualization of gallbladder wall thickening in the presence of gallstones using ultrasound has a positive predictive value of $95 \%$ for the diagnosis of acute cholecystitis. ${ }^{10}$

Carcinoma of gallbladder is a malignant condition but it is not uncommon in our country. Conventionally, carcinoma gallbladder is diagnosed on the basis of medical history; abdominal examination and using modern imaging techniques like transabdominal ultrasonography of upper abdomen. Transabdominal sonography has been found to be useful in suggesting the preoperative diagnosis of carcinoma, ${ }^{12}$ although studies regarding its diagnostic accuracy are rare. The present study was conducted to determine the usefulness of US in diagnosing gallbladder diseases with particular reference to cholecystitis and gall bladder carcinoma.

\section{METHODS:}

This cross-sectional observational study was conducted at the Department of Radiology and Imaging, Rajshahi Medical College, Rajshahi in collaboration with the Departments of General Surgery and Histopathology of the same Medical College over a period of 2 years from July 2016 to June 2018. A total o 135 patients (ranging from 40 - 80 years) were initially included on the basis of signs and symptoms of gallbladder diseases (such as upper abdominal pain, jaundice, low grade fever, weight loss and upper abdominal mass) and underwent USG for preoperative radiological diagnosis, its extension and operability. Of them 7 were minors ( $<18$ years old) and were excluded from the study leaving 128 for final evaluation. All these patients were subjected to abdominal ultrasound to achieve a ultrasonic diagnosis of gall bladder disease followed by histopathological examination of biopsy material taken from the gall bladder or specimen of the operated gall bladder.

The accuracy of ultrasound in the diagnosis of gall bladder diseases was determined by comparing the ultrasound sound diagnosis with that of histopathological diagnosis. In particular, the role of ultrasound was evaluated in the differentiation of benign gall bladder diseases from those of 
malignant ones. The statistical analyses were performed using computer software SPSS (Statistical Package for Social Sciences), version 11.5 and the test statistics used to analyse the data were descriptive statistics

\section{RESULT:}

The ultrasound diagnosis revealed 80 with acute cholecystitis 16 with carcinoma of gall bladder, while histopathology diagnosed 64 as cholecystitis and 13 as malignancy of gallbladder. Age distribution of the patients shows that over one-third $(35.9 \%)$ was 50 or $>50$ years old followed by $24.9 \% 40$ - 50 years, $21.9 \% 30-40$ years and $16.4 \% 20-30$ years old. The mean age of the patients was 43.8 years and the youngest and the oldest patients were 18 and 80 years old respectively. Females outnumbered males by roughly $11: 9$ (Table I). About $72 \%$ of patients had normal BMI, $6.2 \%$ underweight, $16.4 \%$ overweight, and $4.7 \%$ obese. The mean BMI was $23.3 \mathrm{~kg} / \mathrm{m}^{2}$ and the lowest and the highest BMI were 13.3 and $44.7 \mathrm{~kg} / \mathrm{m}^{2}$ (Table II).

The predominant complaints reported by the patients were pain in the right upper abdomen $(95.3 \%)$, epigastric pain $(94.7 \%)$, abdominal discomfort $(96.9 \%)$ followed by nausea $(75 \%)$, low-grade fever $(37.5 \%)$, jaundice $(26.6 \%)$ and vomiting $(26.6 \%)$, yellow colouration of conjunctiva $(25.8 \%)$, dark urine $(18 \%)$, weight loss (17.2\%). Approximately $44 \%$ of the patients exhibited anaemia (Table III). Nearly half (46.1\%) of the patients exhibited sonographic Murphy's sign and in $10.9 \%$ cases presence of a mass was detected. Hyperechoeic echo character was invariably obtained with $12.5 \%$ cases having hypooechoeic character as well (Table IV).

Over $90 \%$ of the patients had gall-stones, $62.5 \%$ cholecystitis (thickened gall-bladder wall), 3.1\% empyema gall-bladder, $7.8 \%$ sludge, $10.9 \%$ dilated common bile duct $\& 39.1 \%$ pericholecystic fluid (Table-V). Ultrasound comment on the type of diseases revealed that $112(87.5 \%)$ were benign diseases and $16(12.5 \%)$ malignant cases (Fig.1). Approximately $55 \%$ of the gall bladder diseases diagnosed by histopathology were cholecystitis,
$35 \%$ were pericholecystic fluid and $4.7 \%$ were sludge (Table VI). Histopathological comment shows that about $90 \%$ of the diseases were benign and the rest (10.2\%) were malignant (Fig.2).

\begin{tabular}{|c|c|c|c|}
\hline $\begin{array}{l}\text { Demographic } \\
\text { variables }\end{array}$ & Frequency & Percentage & $\begin{array}{c}\text { Mean } \pm \text { SEM } \\
\text { (range) }\end{array}$ \\
\hline \multicolumn{4}{|l|}{ Age (yrs) } \\
\hline$<20$ & 2 & 1.6 & \multirow{5}{*}{$\begin{array}{c}43.8 \pm 14.4 \\
(18-80)\end{array}$} \\
\hline $20-30$ & 21 & 16.4 & \\
\hline $30-40$ & 28 & 21.9 & \\
\hline $40-50$ & 31 & 24.2 & \\
\hline$\geq 50$ & 46 & 35.9 & \\
\hline \multicolumn{4}{|l|}{ Sex } \\
\hline Male & 59 & 43.7 & --- \\
\hline Female & 76 & 56.3 & --- \\
\hline
\end{tabular}

TABLE II. Distribution of patients by their demographic variables

\begin{tabular}{lccc} 
BMI $(\mathrm{kg} / \mathrm{m} 2)$ & Frequency & Percentage & $\begin{array}{c}\text { Mean } \pm \text { SEM } \\
\text { (range) }\end{array}$ \\
\hline 18.5 (Underweight) & 8 & 6.2 & \\
$18.5-25$ (Normal) & 92 & 71.9 & \\
$25-30$ (Overweight) & 21 & 16.4 & $23.3 \pm 3.8$ \\
$30-40$ (Obese) & 6 & 4.7 & $(13.3-44.7)$ \\
$\geq 40$ (Morbidly obese) & 1 & 0.8 &
\end{tabular}

TABLE III. Distribution of the patient by their clinical characteristics

$\begin{array}{lcc}\text { Clinical characteristics } & \text { Frequency } & \text { Percentage } \\ \text { Pain in the right upper abdomen } & 122 & 95.3 \\ \text { Epigastric pain } & 121 & 94.7 \\ \text { Abdominal discomfort } & 124 & 96.9 \\ \text { Low grade fever } & 48 & 37.5 \\ \text { Jaundice } & 34 & 26.6 \\ \text { Nausea } & 96 & 75.0 \\ \text { Vomiting } & 34 & 26.6 \\ \text { Diarrhoea } & 7 & 5.5 \\ \text { Yellow coloration of conjunctiva } & 33 & 25.8 \\ \text { Dark urine } & 23 & 18.0 \\ \text { Anaemia } & 56 & 43.8 \\ \text { Weight loss } & 22 & 17.2 \\ \text { Presence of a mass in the right } & & 10.2 \\ \text { hypochondrium } & 13 & \end{array}$




\begin{tabular}{|c|c|c|}
\hline USG findings & Frequency & Percentage \\
\hline Presence of a mass & 14 & 10.9 \\
\hline Sonographic Murphy's sign & 59 & 46.1 \\
\hline \multicolumn{3}{|l|}{ Echo characteristics } \\
\hline Hypooechoeic & 16 & 12.5 \\
\hline Hyperechoeic & 128 & 100.0 \\
\hline
\end{tabular}

\begin{tabular}{|c|c|c|}
\hline Diseases diagnosed by USG & Frequency & Percentage \\
\hline Gallstones & 117 & 91.4 \\
\hline Cholecystitis / Thickcncd gall-bladder wall & 80 & 62.5 \\
\hline Empyema Gall-bladder & 4 & 3.1 \\
\hline Sludge & 10 & 7.8 \\
\hline Dilated common bile duct & 14 & 10.9 \\
\hline Pericholecystic fluid & 50 & 39.1 \\
\hline Air in the gallbladder wall & 1 & 0.8 \\
\hline
\end{tabular}

*Total will not correspond to $100 \%$ for multiple diagnosis in the same individual

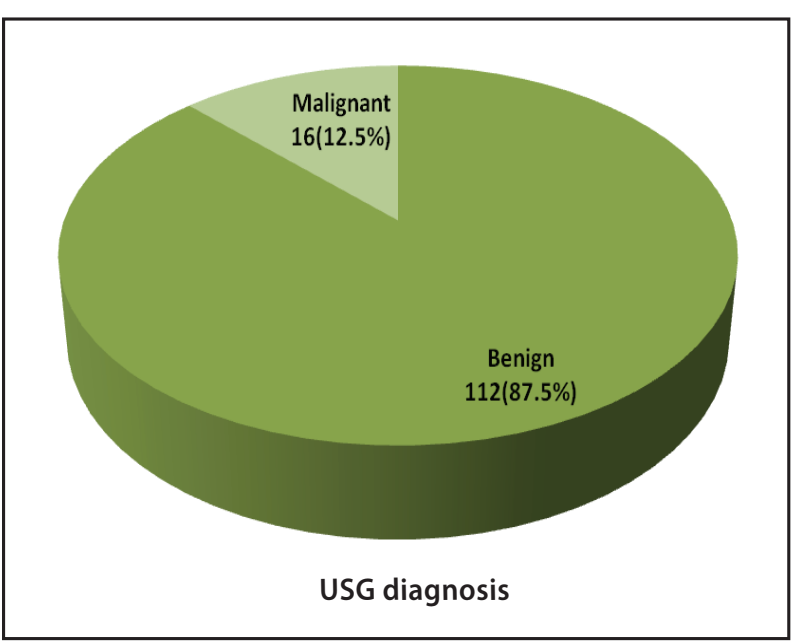

Fig. 1: Distribution of patients by type of diseases diagnosed $(n=128)$

\begin{tabular}{|c|c|c|}
\hline Histological findings & Frequency & Percentage \\
\hline Cholecystitis / Thickened gall-bladder wall & 70 & 54.7 \\
\hline Sludge & 6 & 4.7 \\
\hline Pericholecystic fluid & 45 & 35.2 \\
\hline
\end{tabular}

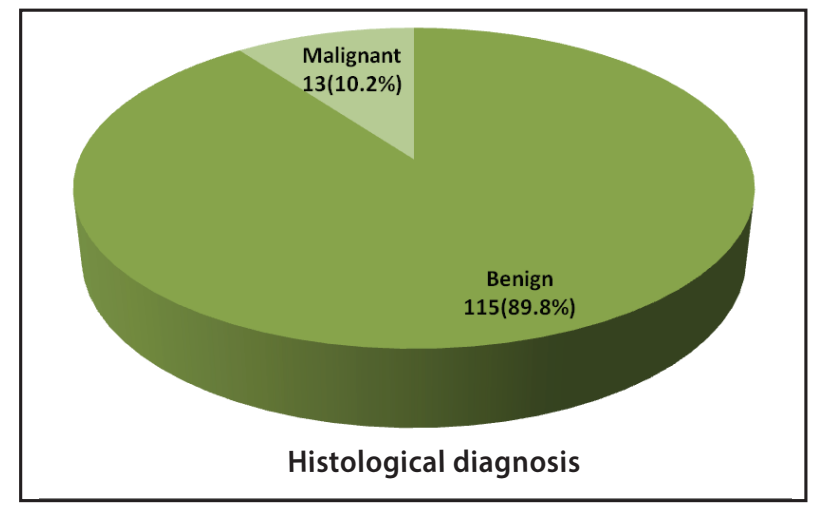

Fig. 2 : Histological type of diseases $(n=128)$

The sensitivity of ultrasound in correctly diagnosing cholecystitis was $85.9 \%$, while the specificity of the test in correctly ruling out those who did not have cholecystitis was $60.9 \%$. The positive and negative predictive values (PPVs) of the test were $68.8 \%$ and $81.2 \%$ respectively. The percentage of false positive and false negative yielded by the test were $31.2 \%$ and $18.8 \%$ respectively. The overall diagnostic accuracy of the test was $73.4 \%$. The sensitivity of Ultrasound in correctly diagnosing carcinoma of gall bladder was $84.6 \%$, while the specificity of the test in correctly differentiating those who did not have carcinoma was $95.6 \%$. The positive and negative predictive values (PPVs) of the test were $68.7 \%$ and $98.2 \%$ respectively. The percentage of false positive and false negative as yielded by the test were $31.2 \%$ and $1.8 \%$ respectively. The overall diagnostic accuracy of the test was $94.5 \%$.

\section{DISCUSSION:}

Acute cholecystitis accounts for $3-10 \%$ of all patients with abdominal pain and is the most common cause of acute abdominal pain in the right upper quadrant, especially in the elderly patients. ${ }^{13}$ In the present study as well $95 \%$ of the patients presented with upper abdominal or epigastric pain and discomfort. The sensitivity of ultrasound in diagnosing cholecystitis was $85.9 \%$, while the specificity of the test was $60.9 \%$. The positive and negative predictive values (PPVs) of the test were $68.8 \%$ and $81.2 \%$ respectively. The overall diagnostic accuracy of the test was $73.4 \%$. Although cholescintigraphy still has the highest 
sensitivity \& specificity ( $96 \%$ and $90 \%$ ) in patients who are suspected of having acute cholecystitis, sonography is still used as the initial imaging technique for evaluating patients with suspected gallbladder (GB) disease because of its high sensitivity at the detection of GB stones, its real-time character, and its speed and portability. ${ }^{14}$ Because of a combination of reasons including logistic drawbacks, broad imaging capability and clinician referral pattern (especially in the emergency setting) the use of cholescintigraphy is limited in clinical practice. ${ }^{6} \mathrm{CT}$ is particularly useful for evaluating the many complications of acute cholecystitis, such as emphysematous cholecystitis, gangrenous cholecystitis, hemorrhage, \& gallstone ileus. ${ }^{15,16}$ Moreover CT is also useful in making the specific diagnosis when obesity or gaseous distention limit the use of US.

Thus, US has emerged as the first-line imaging modality for the diagnosis of acute calculous cholecystitis. In cholescintigraphic procedure the examination time takes up to several hours, whereas a full abdominal US examination is readily available, can be performed in 10-15 minutes, and allows for assessment of pain localized to the gallbladder region (sonographic Murphy sign). ${ }^{17}$ Furthermore, cholescintigraphy provides information confined to the hepatobilliary tract, whereas US can be useful in diagnosing other pathologic conditions responsible for the abdominal complaints. Cholescintigraphy also carries the burden of ionizing radiation whereas US imaging do not. ${ }^{18}$

As the role of ultrasound in the differentiation of gall-bladder carcinoma from the benign diseases was evaluated, it was revealed that the imaging modality has optimum sensitivity $(84.6 \%)$ and high specificity (95.6\%). The positive and negative predictive values of the test were 93.9 and $71.4 \%$ respectively, while the diagnostic accuracy of the test was $90 \%$. Ghafoor et al ${ }^{19}$ conducted a similar study in the BIRDEM, who found a somewhat higher sensitivity $(93.9 \%)$ but a much lower specificity $(71.4 \%)$. Yeh ${ }^{20}$ reported $84.6 \%$ accuracy of US in the diagnosis of the gallbladder carcinoma. Courtney \& Townsend. ${ }^{21}$ described that sensitivity of ultrasound in the detection of gallbladder carcinoma ranges from $70-100 \%$. Although the overall prognosis for this tumor remains poor,

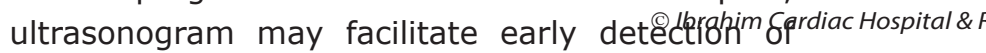
these tumours when they are still localized. Thus, survival time of the patients can be increased by early removal of tumors.

\section{CONCLUSION:}

Summarising the findings of the study it can be concluded that US could be considered the preferred initial imaging technique for patients who are clinically suspected of having acute calculous cholecystitis. It is also a useful imaging modality for diagnosing gall-bladder malignancy. However, it is not suitable for evaluating the complications of acute cholecystitis, such as emphysematous cholecystitis, gangrenous cholecystitis, hemorrhage, and gallstone ileus and for detecting extension of tumor and involvement of surrounding structures including lymph nodes and hepatodudenal ligament which are essential for determining its resectability. Thus, US can be confidently used in the primary evaluation and management of patients suspected of heptobilliary pathology.

\section{REFERENCE:}

1. Singer AJ, Mc Cracken G, Henry MC, Thode HC Jr, Cabahug $\mathrm{CJ}$. Correlation among clinical, laboratory, and hepatobiliary scanning findings in patients with suspected acute cholecystitis. Ann Emerg Med 19;28(3):267-72.

2. Summers SM, Scruggs W, Menchine MD, Lahham S, Anderson C, Amr O, et al. A prospective evaluation of emergency department bedside ultrasonography for the detection of acute cholecystitis. Ann Emerg Med 2010; 56(2):114-22.

3. Menu Y, Vuillerme M-P. Non-traumatic abdominal emergencies: imaging and intervention in acute biliary conditions. In Emergency Radiology. Springer-Verlag Berlin Heidelberg; Marincek B, Dondelinger RF. Imaging and Intervention 2007:481-91.

4. Trowbridge RL, Rutkowski NK, Shojania KG. Does this patient have acute cholecystitis. JAMA 2009;289:80-86.

5. Nino-Marcia M, Jeffrey RB Jr. Imaging the patient with right upper quadrant pain. Semin Roentgenol 2001;36: 81-91. 
6. Shea JA, Berlin JA, Escarce JJ, Clarke JR, Kinosian BP, Cabana MD, Tsai WW, et al. Revised estimates of diagnostic test sensitivity and specificity in suspected biliary tract disease. Arch Intern Med 1994;154(22): 2573-81.

7. Lorusso F, Fonio P, Scardapane A, Giganti M, Rubini G, Ferrante A, Stabile Ianora AA. Gatrointestinal imaging with multidetector CT and MRI. Recenti Prog Med 2012; 103(11):493-9.

8. Reginelli A, Pezzullo MG, Scaglione M, Scialpi M, Brunese L, Grassi R. Gastrointestinal disorders in elderly patients. Radiol Clin North Am 2008;46(4):755-71.

9. Laing FC, Federle MP, Jeffrey RB, Brown TW: Ultrasonic evaluation of patients with acute right upper quadrant pain. Radiology $1981 ; 140(2): 449-55$.

10. Ralls PW, Colletti PM, Lapin SA, Chandrasoma P, Boswell WD Jr, Ngo C, et al. Real-time sonography in suspected acute cholecystitis: prospective evaluation of primary and secondary signs. Radiology 1985;155:767-71.

11. Imhof M, Raunest J, Ohmann C, Röher HD. Acute acalculous cholecystitis complicating trauma: a prospective sonographic study. World J Surg 1992;16(6):1160-65.

12. Paraskevopoulos JA, Baer H, Uttigea F, Dennison AR. The role of imaging techniques in the diagnosis of primarycarcinoma of the gallbladder. Br J Surg 1994;81(1):15

13. Håkansson $\mathrm{K}$, Leander $\mathrm{P}$, Ekberg $\mathrm{O}$, Håkansson H. MR imaging in clinically suspected acute cholecystitis. A comparison with ultrasonography. Acta Radiol 2000;41 (4):322-8.
14. Park MS, Yu JS, Kim YH, Kim MJ, Kim JH, Lee S, Cho N, Kim DG, Kim KW. cute cholecystitis: comparison of MR cholangiography \& US. Radiology 1998;209(3):781-5.

15. Reginelli A, Mandato $Y$, Solazzo A, Berritto D, Iacobellis $F$, Grassi R. Errors in the radiological evaluation of the alimentary tract: part II. Semin Ultrasound CT MR 2012;33(4):308-17;

16. Buonamico P, Suppressa P, Lenato GM, Pasculli G, D'Ovidio $F$, Memeo M, Scardapane A, Sabbà C. Liver involvement in a large cohort of patients with hereditary hemorrhagic telangiectasia: echo-color-Doppler vs. multislice computed tomography study. J Hepatol 2008; 48(5):811-20.

17. Pinto A, Reginelli A, Cagini L, Coppolino F, Ianora AAS, Bracale $R$ et al. Accuracy of ultrasonography in the diagnosis of acute calculous cholecystitis: review of the literature. Critical Ultrasound Journal 2013;5 (Suppl-1): S11.

18. van Breda Vriesman AC, Engelbrecht MR, Smithuis $R H$, Puylaert JB. Diffuse gallbladder wall thickening: differential diagnosis. Am J Roentgenol 2007; 188:495-501.

19. Ghafoor N, Abedin N, Mohiuddin AS. Role of Ultrasound \& Computed Tomography in the Evaluation of Gallbladder Malignancy. AKMMCJ 2017;8(2):105-11.

20. Yeh $\mathrm{H}$. Ultrasonography and computed tomography of carcinoma of the gallbladder. Radio 1979;133:167-73.

21. Courtney M. Townsend Jr. Sabiston Textbook of Surgery: The biological basis of modern surgical practice (textbook of surgery), 17 $7^{\text {th }}$ ed, WB Saunders 2004. 